\title{
Influence of the anti-androgen hydroxyflutamide on in vitro development of mouse embryos
}

\author{
C. Yallampalli, C. Osuamkpe and M. Nagamani \\ Division of Reproductive Endocrinology, Department of Obstetrics and Gynecology, The University of \\ Texas Medical Branch, Galveston, TX 7755-1062, USA
}

\begin{abstract}
Hydroxyflutamide is a potent nonsteroidal anti-androgenic drug extensively used in laboratory investigations. Our present studies were aimed at determining whether this antiandrogen modulates development of embryos in vitro. One-cell and two-cell mouse embryos were collected by flushing the oviducts and cultured in defined culture media in the presence or absence of various doses of hydroxyflutamide. The development of embryos from one-cell and two-cell to blastocyst stage was assessed. Hydroxyflutamide caused a dose-dependent $\left(0-100 \mu \mathrm{g} \mathrm{m}^{-1}\right)$ inhibition of development of both one-cell and two-cell embryos; $100 \%$ inhibition was observed at $20 \mu \mathrm{g} \mathrm{ml}^{-1}$. The adverse effects of hydroxyflutamide on twocell embryo development were completely reversed by testosterone in a dose-dependent manner, but not by oestradiol and progesterone. These results indicate that the antiandrogen hydroxyflutamide inhibits early embryo development suggesting that it may be useful during the preimplantation period for preventing conception.
\end{abstract}

\section{Introduction}

Hydroxyflutamide is a potent, nonsteroidal anti-androgen that has been reported to lack other agonistic or antagonistic hormonal properties (Neri et al., 1972). It binds to androgen receptors and competitively inhibits the binding of testosterone and dihydrotestosterone. This compound has therefore been widely used as an anti-androgen in various studies (Peluso et al., 1980; Clark and Nowell, 1980; Krey et al., 1982; Chandrasekhar et al., 1988; Armstrong et al., 1989). Recent studies from our laboratories indicated that hydroxyflutamide blocks ovulation (Opavsky et al., 1987) through interference with the LH surge at pro-oestrus and is reversed by the administration of LHRH (Chandrasekhar and Armstrong, 1988) or progesterone on the day of pro-oestrus (Chandrasekhar and Armstrong, 1989). In addition, hydroxyflutamide delays the initiation of implantation, fetal development and parturition in pregnant rats and suppresses decidualization after artificial stimulation of the sensitized uterus (Chandrasekhar et al., 1990). The delay in the initiation of implantation by hydroxyflutamide may be due to its effects on embryo development in addition to its effects on uterine receptivity.

The role of androgens in intrafollicular oocyte and follicular maturation, ovulation and embryo development is not well understood. The aim of the present experiments was to determine the effects of hydroxyflutamide on development of mouse embryos in vitro. One- and two-cell embryos were cultured in defined culture media in the presence or absence of various doses of hydroxyflutamide, and the development of embryos was assessed. Our results indicate that hydroxyflutamide inhibits embryo development in vitro.

\section{Materials and Methods}

\section{Materials}

Ham's F-10 culture medium was obtained in powder form from Gibco Laboratories (Grand Island, NY). The media were prepared using Milli-Q-water, adjusted to 278-282 mOsm, filter sterilized and stored at $4^{\circ} \mathrm{C}$ for up to 1 month before use. Dulbecco's phosphate-buffered saline (PBS) was used for embryo collection and was prepared from powder (Gibco). Hydroxyflutamide was a gift from R. O. Neri (Schering Corp.; Bloomfield, NJ). Progesterone, oestradiol, testosterone, hCG and BSA were purchased from Sigma (St Louis, MO).

\section{Embryo collection and culture}

Four-week-old female and 12-week-old male mice $\left(\mathrm{B}_{6} \mathrm{C}_{3} \mathrm{~F}_{1}\right)$ were purchased from Harlan-Sprague Dawley (Houston, TX). Animals were housed under a $12 \mathrm{~h}$ light:12 $\mathrm{h}$ dark regimen for at least 4 days before use. Female mice were superovulated by i.p. injection of 25 iu pregnant mares' serum gonadotrophin (Sigma) followed, after $48 \mathrm{~h}$, by $25 \mathrm{iu} \mathrm{hCG}$. After hCG injection, two females were caged with one male and allowed to mate. Mating was confirmed by the presence of a vaginal plug and females were killed between 10:00 and 14:00 h on day 1 of pregnancy (one-cell embryos) or between 08:00 and 10:00 h on day 2 (two-cell embryos) and embryos were flushed from the oviduct with sterile PBS with $0.3 \%$ BSA, using a 30-gauge needle on a $1 \mathrm{ml}$ syringe. One-cell embryos (with two pronuclei) and two-cell embryos were pooled from several mice with a mouth-operated micropipette and washed through four $1 \mathrm{ml}$ changes of equilibrated Ham's F-10 medium with $0.3 \%$ BSA. Embryos were allocated randomly to the experimental Downloaded from Bioscientifica, com at 04/26/2023 04:57:01AM via free access 


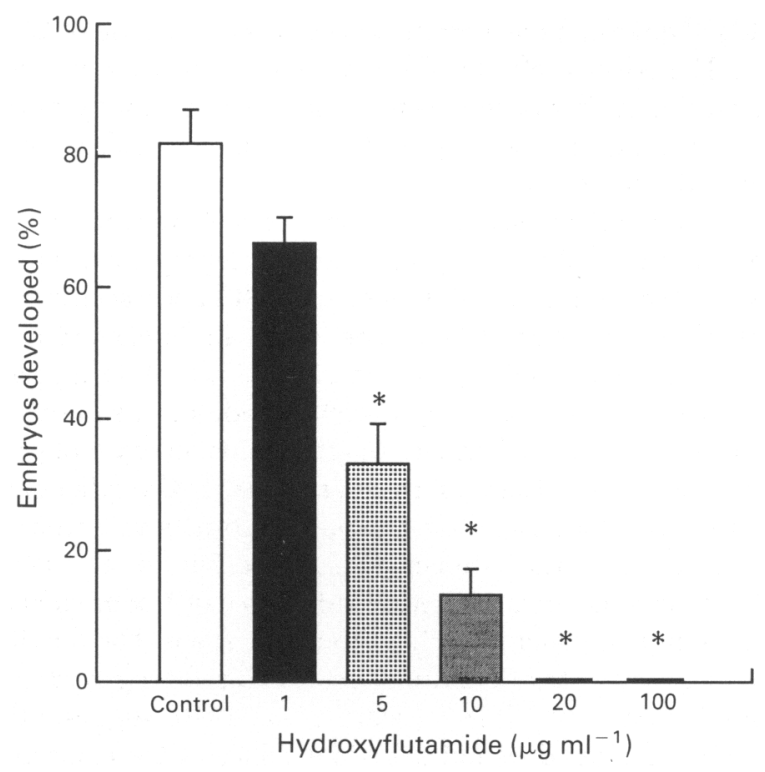

Fig. 1. Development of embryos following culture of one-cell embryos for $96 \mathrm{~h}$ in Ham's F-10 medium with various doses of hydroxyflutamide. Bars indicate the mean percentage of embryos developed in each treatment group. Error bars represent the variation between replicate incubations. ${ }^{*} P<0.01\left(\chi^{2}\right.$ test) compared with control.

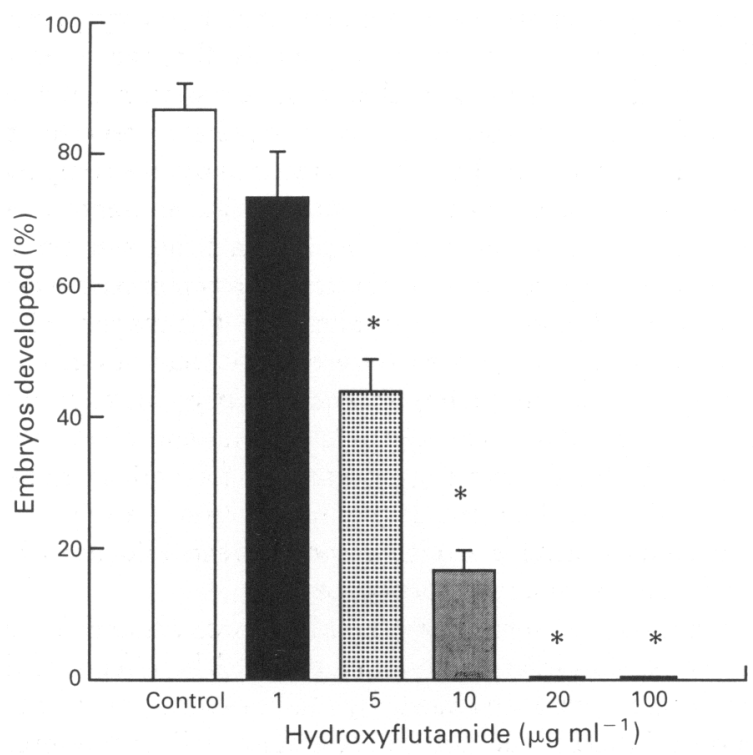

Fig. 2. Development of embryos following culture of two-cell embryos for $72 \mathrm{~h}$ in Ham's F-10 medium with various doses of hydroxyflutamide. Bars indicate the mean percentage of embryos developed in each treatment group. Error bars represent the variation between replicate incubations. ${ }^{*} P<0.01\left(\chi^{2}\right.$ test) compared with control.

treatment groups from the pooled one-cell or two-cell embryos. Stock solutions of hydroxyflutamide, prepared in ethanol, were added to culture medium to give various concentrations $\left(0-100 \mu \mathrm{g} \mathrm{ml}^{-1}\right)$ of hydroxyflutamide but with a constant

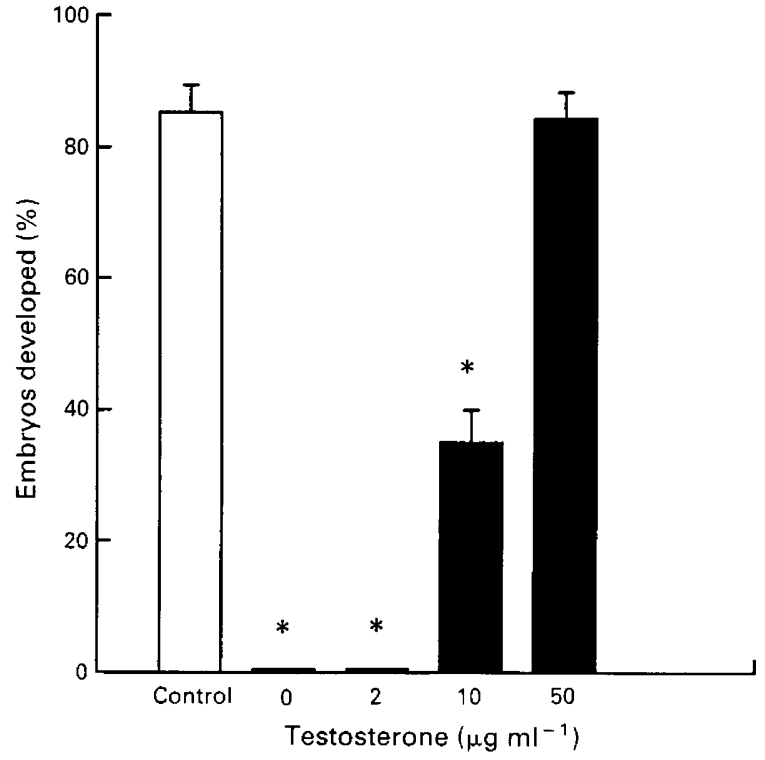

Fig. 3. Dose-dependent effects of testosterone on embryo development in the presence of $20 \mu \mathrm{g}$ hydroxyflutamide $\mathrm{ml}^{-1}$. Each bar represents the mean percentage of embryos developed; error bars indicate the variation between replicate incubations. Embryos were cultured without $(\square)$ or with $20 \mu \mathrm{g}$ hydroxyflutamide $\mathrm{ml}^{-1}(\boldsymbol{\square})$ in the presence of various concentrations of testosterone. ${ }^{*} P<0.01\left(\chi^{2}\right.$ test) compared with control.

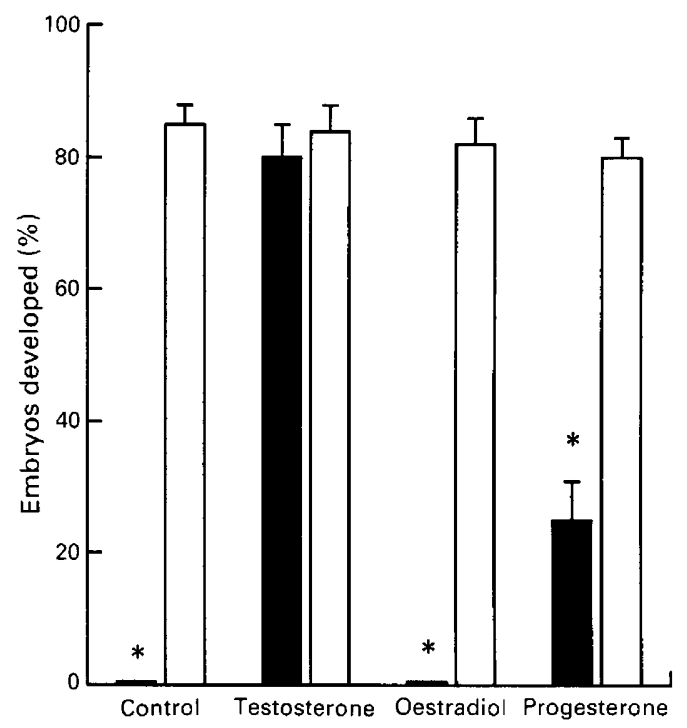

Fig. 4. Modulation by steroid hormones of the effects of hydroxyflutamide on the development of two-cell embryos cultured for $72 \mathrm{~h}$ in Ham's F-10 medium. The medium contained testosterone, oestradiol or progesterone at $50 \mu \mathrm{g} \mathrm{ml}^{-1}$ or vehicle $(\square)$ with or $(\square)$ without $20 \mu \mathrm{g}$ hydroxyflutamide $\mathrm{ml}^{-1}$. Bars indicate the mean percentage of embryos developed in each group with error bars representing the variation between replicate incubations. ${ }^{*} P<0.01\left(\chi^{2}\right.$ test) compared with the respective control. 
ethanol concentration $(0.05 \%)$, immediately before use. Controls received the same concentration of ethanol. In some experiments two-cell embryos were incubated with 2,10 or $50 \mu \mathrm{g}$ testosterone $\mathrm{ml}^{-1}, 50 \mu \mathrm{g}$ oestradiol ml ${ }^{-1}, 50 \mu \mathrm{g}$ progesterone $\mathrm{ml}^{-1}$ in the presence or absence of $20 \mu \mathrm{g}$ hydroxyflutamide $\mathrm{ml}^{-1}$. Embryos were cultured in $50 \mu \mathrm{l}$ drops under autoclaved mineral oil (Sigma) that had been equilibrated in $5 \% \mathrm{CO}_{2}$ before use. Ten to twenty embryos per drop were maintained at $37^{\circ} \mathrm{C}$ under $5 \% \mathrm{CO}_{2}$ in air. Triplicate cultures were established within each individual experiment and each experiment was repeated three to seven times. Embryos were cultured for 72 or $96 \mathrm{~h}$ and scored, daily up to four days for progression to two-cell, fourcell, morula and blastocyst stages. Scoring of embryos was carried out in a blind fashion by a single observer for all the experiments.

\section{Statistical analysis}

The percentage of embryos that had developed to the blastocyst stage in control and various treatment groups were compared using $\chi^{2}$ analysis.

\section{Results}

The presence of hydroxyflutamide in the culture media significantly $(P<0.01)$ reduced the percentage of embryos developing to blastocysts; the effects were dose dependent. Development of both one-cell and two-cell embryos were affected similarly by hydroxyflutamide (Figs 1 and 2). The percentage of embryos developing to blastocysts was reduced in the presence of $1-10 \mu \mathrm{g}$ hydroxyflutamide $\mathrm{ml}^{-1}$ and the development was totally arrested at $20-100 \mu \mathrm{g}$ hydroxyflutamide $\mathrm{ml}^{-1}$. In the embryos exposed to $20 \mu \mathrm{g}$ hydroxyflutamide $\mathrm{ml}^{-1}$ and higher doses, the development was arrested at the two-cell stage. The presence of ethanol did not alter the development of one-cell or two-cell embryos.

We next investigated whether the hydroxyflutamideinduced arrest of embryo development could be reversed by steroid hormones. Testosterone reversed the inhibition by $20 \mu \mathrm{g}$ hydroxyflutamide $\mathrm{ml}^{-1}$ in a dose-dependent manner. Complete reversal of the inhibition was observed in the presence of $50 \mu \mathrm{g}$ testosterone $\mathrm{ml}^{-1}$ (Fig. 3). In addition, the ability of oestradiol and progesterone, at $50 \mu \mathrm{g} \mathrm{m}^{-1}$, to rescue mouse embryos from development arrest caused by $20 \mu \mathrm{g}$ hydroxyflutamide $\mathrm{ml}^{-1}$ was also tested. Oestradiol was ineffective in restoring the embryo development (Fig. 4). However, progesterone had a positive effect; about $35 \%$ of the embryos developed to blastocysts (Fig. 4). The embryo development, in the absence of hydroxyflutamide (Fig. 4), was unaffected in the presence of testosterone, oestradiol or progesterone; the percentage of embryos developing from the two-cell to blastocyst stage was similar to that without steroids.

\section{Discussion}

This report is the first direct evidence of inhibition of embryo development by the anti-androgen hydroxyflutamide. Hydroxyflutamide arrested the embryo development of both one-cell and two-cell embryos. The inhibition was dose depen- dent, and developmental arrest was obtained at a dose of $20 \mu \mathrm{g}$ $\mathrm{ml}^{-1}$. The adverse effects of hydroxyflutamide were reversed by testosterone in a dose-dependent manner, but not by oestradiol and progesterone, suggesting a role for androgens in embryo development.

Our previous studies demonstrated that hydroxyflutamide when injected daily on day 4,5 and 6 of pregnancy in rats causes a delay in implantation of embryos (Chandrasekhar $e$ t al, 1990; Chandrasekhar, 1991). The delay in implantation of embryos in these studies (Chandrasekhar et al., 1990) appeared to be due to the effects of hydroxyflutamide on the uterus, as unimplanted embryos, flushed from the uterus on day 6 of pregnancy, were at the blastocyst stage and when hydroxyflutamide treatment was terminated on day 6, these blastocysts went on to implant. In these studies (Chandrasekhar et al, 1990), hydroxyflutamide treatment was started on day 4 of pregnancy, when embryos would be at the blastocyst stage. The fact that these blastocyst-stage embryos were viable during hydroxyflutamide treatment (Chandrasekhar et al., 1990) suggests that this anti-androgen does not affect the ability of the embryo to implant. However, in the study reported here the early stages of embryo development were significantly arrested by hydroxyflutamide. Data from this study together with our previous studies (Chandrasekhar et al., 1990; Chandrasekhar, 1991) raise the possibility that hydroxyflutamide may be used as an antigestational drug.

From these earlier studies in vivo (Chandrasekhar et al., 1990) it was unclear whether hydroxyflutamide had direct effects on embryo viability and its development. Results from the present in vitro study support the contention that hydroxyflutamide inhibits development of embryos, possibly through its direct actions on the embryo. The ability of testosterone, but not oestradiol and progesterone, to completely reverse the developmental arrest of the embryos induced by this compound indicates that these effects are specific to anti-androgenic properties of hydroxyflutamide. Although progesterone and oestradiol are required in vivo for complete embryo development in utero (Roblero, 1973; Roblero and Garavagno, 1979), there is no convincing evidence for direct effects of oestradiol and progesterone on preimplantation embryo development. Several workers (Paria and Dey, 1990; Mattson et al., 1988; Colver et al., 1991) have suggested roles for various growth factors in the development of preimplantation embryos. Our present studies provide evidence for a direct influence of an anti-androgen on embryo development.

In summary, we demonstrated that hydroxyflutamide inhibits preimplantation embryo development. The effects of this anti-androgen were reversed by testosterone in a dosedependent fashion, but not by oestradiol and progesterone. These findings may have important clinical implications in the development of antigestational drugs for early embryo development.

\section{References}

Armstrong DT, Siuda A, Opavsky MA and Chandrasekhar Y (1989) Bimodal effect of luteinizing hormone and role of androgens in modifying superovulatory responses of rats to infusion with purified porcine folliclestimulating hormone Biology of Reproduction 41 54-62

Chandrasekhar Y (1991) Effects of hydroxyflutamide on female reproductive function Advances in Contraceptive Delivery Systems 7 157-166 
Chandrasekhar Y and Armstrong DT (1988) Human chorionic gonadotropin and luteinizing hormone-releasing hormone reverse the blockade of ovulation in pregnant mares serum gonadotropin-primed immature rats by the anti-androgenic drug, hydroxyflutamide Canadian Joumal of Physiology and Pharmacology 66 783-787

Chandrasekhar $Y$ and Armstrong DT (1989) Ability of progesterone to reverse anti-androgen (hydroxyflutamide)-induced interference with the preovulatory LH surge and ovulation in PMSG-primed immature rats Journal of Reproduction and Fertility 85 309-316

Chandrasekhar Y, Opavsky MA and Armstrong DT (1988) Role of androgens in ovulation inhibition in rats superovulated with FSH preparations containing high LH activity Theriogenology 29234 (Abstract)

Chandrasekhar Y, Armstrong DT and Kennedy TG (1990) Implantation delay and antideciduogenic activity in the rat by the anti-androgen, hydroxyflutamide Biology of Reproduction 42 120-125

Clark CR and Nowell NW (1980) The effect of the non-steroidal anti-androgen flutamide on neural receptor binding of testosterone and intermale aggressive behaviour of mice Psychoneuroendocrinology 5 39-45

Colver RM, Howe AM, McDonough PG and Boldt J (1991) Influence of growth factors in defined culture medium on in vitro development of mouse embryos Fertility and Sterility 55 194-199

Krey LC, MacLusky NJ, Davis PG, Liebenburg I and Roy EJ (1982) Different intracellular mechanisms underlie testosterone's suppression of basal and stimulation of cyclic luteinizing hormone release in male and female rats Endocrinology 110 2159-2167

Mattson BA, Rosenblum IY, Smith RM and Heyner S (1988) Autoradiographic evidence for insulin and insulin-like growth factor binding to early mouse embryos Diabetes 37 585-589

Neri R, Florance K, Koziol P and van Cleave S (1972) A biological profile of a nonsteroidal anti-androgen, SCH 13521 (4'-nitro-3'-trifluoro-methylisobutyranilide) Endocrinology $91427-437$

Opavsky MA, Chandrasekhar Y, Roe M and Armstrong DT (1987) Interference with the preovulatory luteinizing hormone surge and blockade of ovulation in immature PMSG-primed rats with the anti-androgenic drug, hydroxyflutamide Biology of Reproduction 36 636-642

Paria BC and Dey SK (1990) Preimplantation embryo development in vitro: cooperative interactions among embryos and role of growth factors Proceedings of National Academy of Sciences USA 87 4756-4760

Peluso JJ, Stude D and Steger RW (1980) Role of androgens in hCG-induced ovulation in PMSG-primed immature rats Acta Endocrinologica 93 505-512

Roblero LS (1973) Effect of progesterone in vivo upon the role of cleavage of mouse embryos Joumal of Reproduction and Fertility 35 153-155

Roblero LS and Garavagno AC (1979) Effect of oestradiol-17 $\beta$ and progesterone on oviductal transport and early development of mouse embryos Joumal of Reproduction and Fertility 57 91-95 